\title{
Problem popularizacije strokovnih besedil: analiza medijskih diskurzov o ljubljanskem urbanizmu
}

\section{The problem of popularisation of expert texts: Analysis of media discourses on Ljubljana urbanism}

\begin{abstract}
V obdobju po osamosvojitvi Slovenije je v strokovni in poljudni publicistiki s področja prostorskega načrtovanja mogoče opaziti več instrumentalnih, marketinško motiviranih prepričevalnih dejavnosti. Medijsko močno podprti partikularizmi so problematični predvsem z vidika izključevanja oz. zmanjševanja vpliva vsebinskega, argumentativno-substancialnega javnega razpravljanja. Osnovni namen članka je prispevati k jasnejši razgrnitvi razmerij in procesov prostorskega načrtovanja v Ljubljani. Pri tem se opiramo na kvantitativno in kvalitativno analizo besedil ter z reprezentativnimi primeri o konkretnih aktualnih mestnih načrtih pokažemo prikrite vsebine, eksplicitne in implicitne ideološke konstrukcije, interesno pogojene partikularizme in strategije prikrivanja $v$ strokovnih in poljudnih publikacijah, ki se ukvarjajo s prostorskimi temami.
\end{abstract}

KLJUČNI POJMI: analiza prostorskih politik, urbani razvoj, javni/ zasebni interesi, kvantitativna analiza besedil, kvalitativna analiza besedil.

\section{Uvod}

V dokaj kratkem obdobju po uvedbi tržne ekonomije v Sloveniji je opaziti, da so različne (ekonomske) interesne skupine oz. »urbani managerji« (Pahl, 1977: 50) postali pomemben dejavnik v prostorskem načrtovanju. Urbani managerji, ki jih v žargonu pogosto označujemo tudi z izrazom »developerji«, uporabljajo vrsto komunikacijskih tehnik za zagotavljanje zadostne podpore javnosti pri posegih v prostor. Pri tem se pogosto pojavlja selekcioniranje oz. "filtriranje " problematik in argumentov v medijih, s čimer se pozornost javnosti preusmerja na zgolj določene oz. vnaprej izbrane teme. Z zamolčanjem in potlačitvijo določenih pomembnih tematik nastajajo poskusi usmerjanja javnega mnenja in zmanjševanja
In the period after the post-socialist transition of Slovenia we can notice an increased number of instrumental, marketing oriented public relation (PR) activities in expert and popular media from the field of spatial planning. The problem of instrumentalisation of media discourses reflects in exclusion i.e. deficiency of content-argumentative language in public debate. The basic purpose of the article is to analyse and expose some of the relationships and processes that have great influence in the space of the city and its surroundings. The article draws on empirical evidence from quantitative and qualitative analyse of texts and pays attention to some of the actual cases in spatial planning that show hidden contents, explicit and implicit ideological constructions, particularisms of interest groups and strategies of instrumental marketing campaigns.

KEY WORDs: analyse of spatial politics, urban development, public/ private interests, quantitative analyse of text, qualitative analyse of text.

kritičnega naboja javnosti pri izražanju mnenj o posegih $\mathrm{v}$ prostor.

Interesne skupine prepoznajo medijske reprezentacije o posegih $\mathrm{v}$ prostor kot obliko »družbene prakse, prek katere se komunikativna racionalnost in način delovanja prenaša do ljudi« (Salovaara-Moring, 2004: 56) in so uporabljene kot vir za pridobivanje legitimizacije $\mathrm{v}$ potencialno konfliktnih situacijah. V podobnem kontekstu Habermas (1976) omenja, da je pravzaprav nemogoče ločiti sistem političnega odločanja in ekonomije od življenjskega sveta. Oba sistema sta močno prepletena, saj mediacijsko strukturo med njima predstavljajo javnost, sistem komunikacij in konvencije medijsko diskurzivnih praks. 
V članku bo predstavljeno, kako različni mediji prikazujejo današnje prostorske projekte in kako dostop do medijev deluje kot izrazito pomemben strateški vir, ki je pogosto uporabljen oz. "zlorabljen« V odnosu do javnega interesa. Sistemi ekonomske in politične moči, ki se opirajo na procese legitimizacije, pogosto temeljijo na instrumentalni racionalnosti oz. racionalnosti, ki »vse podreja maksimizaciji učinkovitosti« (Chouliaraki, Fairclough, 1999: 12) namesto razvijanja demokratičnih idealov, spodbujajoč »čustva, norme in prepričanja, ki krepi občutenje prostora, varnost in identiteto življenjskega sveta ljudi« (Salovaara-Moring, 2004: 57).

Članek se opira na podatke, ki smo jih pridobili v raziskovalnem projektu Diskurzivna analiza besedil o ljubljanskem urbanizmu (2006). ${ }^{[1]}$ Kot ključno administrativno, politično središče Slovenije je Ljubljana osrednji del prostorskega sistema in najbolj propulzivno območje družbeno-prostorskih sprememb. V tem kontekstu je za Mestno občino Ljubljana nadvse pomembno, da ima ustrezne informacije in jasen vpogled $v$ javne razprave, ki zadevajo prostorskega prostorsko načrtovanje $\mathrm{v}$ mestu. Eden izmed osnovnih namenov raziskovalnega projekta je bilo razločevanje oz. določanje pomembnih razlik med dejanskimi (aktualnimi) in potencialni$\mathrm{mi}$ (navideznimi) interesi, odnosi in procesi $\mathrm{v}$ prostoru. Na najbolj splošni ravni ugotavljamo, da se strokovna in časopisna oz. poljudna besedila močno razlikujejo po podajanju informacij in refleksije o dogodkih v prostoru. Diskrepanca med strokovnimi in poljudnimi besedili pomeni veliko nevarnost za uveljavljanje javnih interesov v mestu. Prav zato je izredno pomembno razkrivanje skritih tendenc, ki so vpete med takšno konstelacijo objavljenih tekstov in kažejo, kako se pomanjkanje refleksije pogosto nadomešča $s$ »strokovnim interpretativnim vakuumom«, ki odpira poti za instrumentalne, marketinško orientirane PR (public-relation) kampanje v procesih prostorskega načrtovanja.

Problem strokovnega interpretativnega vakuuma oz. umanjkanja vsebinsko-argumentativnega jezika v tekstih o ljubljanskem urbanizmu se kaže še izraziteje, ko se medijsko podprte partikularizme prikazuje kot generaliziran javni interes brez resnega, substancialnega javnega razpravljanja. Ob tem je treba poudariti, da si zagovornikov partikularizmov v diskusijah o prostorskem načrtovanju ne zamišljamo kot nepričakovano ali nelegitimno obliko poseganja $\mathrm{v}$ družbeno-prostorsko ureditev, temveč postajajo problematičen dejavnik kvečjemu zaradi neprepričljivih intervencij predstavnikov in zagovornikov javnih interesov. Zaradi teh razlogov bomo posebno pozornost namenili analizi reprezentativnih tekstov o dejanskih prostorskih intervencijah $\mathrm{v}$ mestu, v katerih se kažejo skriti pomeni, implicitna sporočila in prepričevalne strategije različnih interesnih skupin.

$\mathrm{Na}$ začetku članka bodo na kratko predstavljena izhodišča raziskave, nato bomo prešli k razpravi o pomembnejših teoretskih konceptih in metodoloških domnevah, ki se nanašajo na analizo besedil. Sledil bo ključni del: primerjalna analiza tekstov o ljubljanskem urbanizmu. Pri tem bomo prikazali, kako različne discipline oz. strokovni krogi, iz katerih izhajajo avtorji, proizvajajo vrsto diskurzov, ki lahko močno vplivajo na bralce. $V$ sklepu sta podana kratka razprava o učinkih strokovnega interpretativnega vakuuma $v$ tiskanih medijih in njegov pomen za prostorsko načrtovanje v Sloveniji.

\section{Opis analitičnih metod}

Pri pripravi konceptualne sheme za analizo pomenskih sistemov v tiskanih medijih smo upoštevali več kvalitativnih metod. Uporabili smo nekatera interpretativna orodja kritične diskurzivne analize (Fairclough, 1992, 1995) in pragmatike (Verschueren, 1995). Čeprav obstaja vrsta razlik med navedenima pristopoma, oba izhajata iz socialnega konstrukcionizma. Ob tem je treba omeniti, da metodološki pristop v naši raziskavi ni natančno sledil konceptualnim shemam specifičnih avtorjev, temveč je bil uporabljen kot oblika "mešanega« pristopa, v katerem smo kombinirali kvalitativno in kvantitativno analizo besedil. Naš glavni namen je bil oblikovati pristop, s katerim bi preprosto in primerno raziskali ter razkrili strukturo produkcije pomenov $\mathrm{v}$ primeru besedil o ljubljanskem urbanizmu.

Ena izmed osnovnih domnev diskurzivne analize je, da uporaba jezika vključuje družbene posledice. Iz tega izhodišča smo domnevali, da medijski diskurzi o prostorskem načrtovanju $\mathrm{v}$ Ljubljani vplivajo na aktualno prostorsko politiko v mestu. Če povzamemo tezo, da je diskurz »jezik, zamišljen kot družbena praksa (Fairclough, 1995: 135), lahko domnevamo, da se oblast in vpliv ne kažeta le s formalnimi odločevalskimi strukturami, temveč tudi v ustvarjanju in distribuciji idej ter podob oz. konstrukciji diskurzov. Cruikshank (2003: 4) opaža, da "glede na domnevo, da ta oblika oblasti deluje bolj subtilno kot različne formalne oblike oblasti in jo je torej teže identificirati, jo imajo nekateri za ključni vir moči«. Mehanizmi diskurzivne analize so pomembni prav zaradi zmožnosti razkrivanja implicitnih pomenov. V kontekstu naše raziskave nam kažejo, kako so se določene ideje o intervencijah v prostoru izoblikovale in zakaj jih ne bi smeli dojemati kot objektivne, substancialno 
podprte resnice. Z razkrivanjem načinov formiranja idej kvalitativna analiza besedil odpira možnosti za drugačen pristop $\mathrm{k}$ javnim razpravam o posegih $\mathrm{v}$ prostor mesta.

Obstaja vrsta različnih opredelitev diskurza. Potter in Wetherell (1987: 7) ga opredeljujeta kot »vse oblike govorjene interakcije, tako formalne in neformalne, in vključuje tekst, zapisan v vseh možnih oblikah«. Diskurz pomeni tudi »rabo jezika v odnosu do družbenih, političnih in kulturnih oblik - diskurz je jezik, ki odraža družbeni red, in hkrati jezik, ki oblikuje družbeni red in posameznikovo interakcijo z okoljem« (Jaworski, Coupland, 1999: 3). Pomembno je, da diskurza ne identificiramo zgolj kot oblike pogovora, saj se »nanaša na vse načine, s katerimi komuniciramo drug z drugim, in zaobjema široke mreže znakov, simbolov in praks, prek katerih osmišljamo naš(e) svet(ove) za nas in druge« (Gregory, 1986: 11). Diskurzi so lahko oblikovani kot »vzorci argumentacije« (Cruikshank, 2003: 4) v smislu, da so mnenja o določeni temi lahko povezana $z$ drugimi mnenji, ki se navezujejo na sorodno temo. Glede na številne povezave med sorodnimi temami imajo diskurzi oblike »trdnih « struktur, ki imajo »notranjo logiko med različnimi mnenji in pomeni, povezanimi z njimi« (prav tam). Ključni predmet diskurzivne analize torej niso razdrobljene izjave, ki jih najdemo v tekstu, temveč celotni vzorci pomenov oz. pomenski sistemi, ki jih analiziramo glede na posamezne faze raziskovalnega procesa (Slika 1).

Naša baza je vključevala več kot 200 besedil $^{[2]} \mathrm{V}$ različnih formatih ${ }^{[3]}$, ki so bila objavljena $\mathrm{v}$ dnevnem

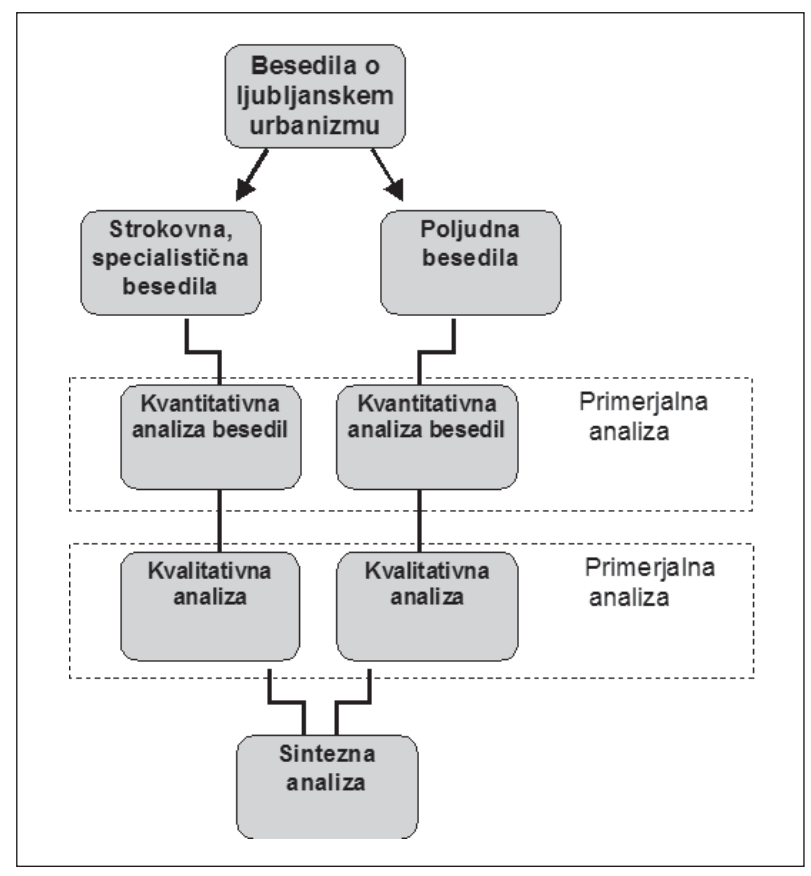

Slika 1: Shema raziskovalnega procesa. časopisju oz. dnevnikih, tednikih in strokovnih, specialističnih (akademskih) publikacijah. Baza je vključevala vsa besedila, ki so bila objavljena v obdobju devetih let (1997-2006). V prvem koraku smo večjo skupino besedil razdelili na dve manjši, ki sta nas posebej zanimali. V prvo so bila vključena »strokovna oz. specialistična besedila« (akademske revije, specializirane publikacije ipd. $)^{[4]}$, v drugo skupino pa "poljudna besedila« (časopisni članki, revije, letaki ipd.). ${ }^{[5]} \mathrm{V}$ drugem koraku je sledila kvantitativna analiza besedil za vsako skupino tekstov. Pri tem smo izdelali vrsto frekvenčnih list za poljudna in strokovna besedila, ki jim je pozneje, v tretjem koraku, sledila kritična diskurzivna analiza, s katero smo analizirali različne medijske diskurze. $\mathrm{V}$ vsakem izmed dveh korakov (drugi in tretji korak) smo posebno pozornost namenili primerjalni analizi obeh skupin besedil. Primerjalna analiza je bila glavno analitično orodje, ki je pokazalo, katere so ključne razlike in podobnosti med navedenima skupinama besedil.

\section{Kvantitativna analiza besedil}

Pri vsebinski analizi besedil smo uporabili različne tehnike filtriranja. V osnovi so bila vsa besedila o ljubljanskem urbanizmu že v začetku selekcionirana na podlagi tematik in besed ter fraz, ki so povezane z urbanizmom. Na primer, koren urban*, ki lahko ustreza besedi URBANizem, URBANost, URBANizacija ipd., je bil uporabljen za razločevanje med besedili, ki se ukvarjajo $\mathrm{z}$ urbanizmom, in večjim številom drugih besedil. Po osnovni selekciji besedil smo v naslednji fazi raziskave besedila analizirali s pomočjo statističnega programa TextSTAT 2.6. Rezultat analize so bile številčne frekvenčne liste

Preglednica 1: Primerjava koeficienta pogostosti termina (KP) za skupini strokovnih in poljudnih besedil.

\begin{tabular}{|l|c|c|}
\hline \multicolumn{1}{|c|}{ Termini $^{[7]}$} & $\begin{array}{c}\text { KP } \\
\text { Strokovna besed. }\end{array}$ & $\begin{array}{c}\text { KP } \\
\text { Poljudna besed. }\end{array}$ \\
\hline DOSTOP* & $\mathbf{0 , 0 8 3}$ & 0,010 \\
\hline RAZVOJ* & 0,970 & 0,140 \\
\hline TRAJNOSTN* & 0,050 & 0,008 \\
\hline PLAN* $^{*}$ & 0,310 & 0,050 \\
\hline EKONOM* & 0,099 & 0,018 \\
\hline GLOBAL* $^{*}$ & 0,050 & 0,010 \\
\hline POLITI* $^{*}$ & 0,165 & 0,060 \\
\hline PROBLEM $^{*}$ & 0,150 & 0,090 \\
\hline STROK* & 0,150 & 0,210 \\
\hline EKOLOG* $^{*}$ & 0,005 & 0,000 \\
\hline STRUKTUR & 0,250 & 0,000 \\
\hline
\end{tabular}

Vir: Kos, D. in dr. (2006) 
besed, uporabljene v besedilih. Frekvenčne liste so omogočile vpogled v »slovar « specifičnih skupin besedil. Razlike med dvema slovarjema so pokazale ne le, katere teme so pomembne za avtorje v specifičnih skupinah besedil, temveč še pomembneje, pokazale so, kako oz. katere besede izbirajo avtorji, ko poročajo o določenem dogodku (Preglednica 1). Za poenostavitev in lažjo primerjavo skupin besedil smo izračunali koeficient pogostosti termina (v Preglednici 1 označen kot KP).[6] Koeficient pogostosti termina nam je omogočil primerjavo med dvema po številu besedil različnima skupinama tekstov.

Primerjava med skupinama strokovnih in poljudnih besedil kaže razlike v uporabi slovarja. V strokovnih besedilih so besede, kot so razvoj, planiranje, struktura, ekonomija, dostopnost, globalizacija, trajnostni razvoj, pogosteje uporabljene. Največja razlika med skupinama tekstov je opazna pri terminu »dostopnost«, ki je v strokovnih besedilih uporabljen 8,3-krat pogosteje kot $\mathrm{v}$ časopisnih, poljudnih besedilih. Dostopnost je brez dvoma eden izmed ključnih urbanističnih konceptov, ki ga temu ustrezno pogosteje opažamo v strokovnih in manj v poljudnih besedilih. Razlike med besedili so se pokazale tudi pri rabi besed, kot so razvoj, trajnostni razvoj, planiranje, ekonomske (dimenzije urbanizma) in globalizacijski (procesi). Avtorji strokovnih besedil so nagnjeni k pogostejši uporabi abstraktnejših besed, pri čemer bralce nagovarjajo iz položaja avtoritete, medtem ko se avtorji poljudnih besedil pogosteje sklicujejo na stroko. Avtorji poljudnih besedil pogosteje uporabljajo termine: strokovnjak, ekspert, ekspertiza in strokovno znanje, ki bi bili lahko indikator kritične samorefleksije oz. zavedanja o pomanjkanju znanja o urbanizmu. Ob tem je treba omeniti, da čeprav se avtorji poljudnih besedil pogosteje opirajo na strokovno znanje, to še ne pomeni, da ne izključujejo oz. se namerno izogibajo določenim pomembnim dimenzijam prostorskega načrtovanja, kot je na primer ekološka problematika.

Izbira določene vrste besedišča ni naključen element, temveč pomemben indikator mnenja komentatorja oz. pisca besedila v odnosu na dogodek, ki ga opisuje, komentira. Če je avtor besedila obenem tudi edini mediator oz. posrednik med dogodkom in publiko, potem njegova izbira besed vpliva na mnenje bralcev o določenem dogodku. Poleg prikaza osnovnih razlik pri rabi besed med strokovnimi in poljudnimi besedili nam je frekvenčna porazdelitev pojmov omogočila tudi identifikacijo različnih diskurzov. S preučitvijo, kje v besedilu so določene besede in kako se povezujejo $\mathrm{z}$ drugimi besedami oz. kako so vključene $\mathrm{v}$ diskurzivni kontekst, smo lahko izoblikovali seznam diskurzov, ki so bili podrobneje analizirani $\mathrm{v}$ tretjem koraku raziskovalnega projekta.

\section{Kvalitativna analiza besedil}

\subsection{Diskurzivne strategije - identifikacija (ideološkosti) diskurzov}

Osnovni namen diskurzivne analize je bil prikazati specifične pomenske vzorce oz. pomenske sisteme, ki so jih avtorji uporabljali v besedilih o ljubljanskem urbanizmu. Pri njihovem iskanju smo veliko pozornosti namenili »diskurzivnim strategijam" (Wallwork, Dixon, 2004: 32) ${ }^{[8]}$, ki olajšajo reifikacijo oz. opredmetijo, kvantificirajo pomen določenih vrednot, praks in identitet. Analiza specifičnih diskurzivnih strategij nam $\mathrm{z}$ analizo retoričnih mehanizmov razkrije implicitne ideološke pomene tekstov. V naši analizi besedil so diskurzivne strategije opozarjale na netransparentnosti $\mathrm{v}$ tekstih, ki jih je zato potrebno nadalje analizirati. Diskurzivne strategije delujejo kot orodje, ki razkriva, kakšne retorične strategije uporabljajo avtorji, da bi dosegli javno podporo in legitimacijo svojih idej in konceptov. Prikazane so tri diskurzivne strategije, ki so pogosto uporabljene $\mathrm{v}$ besedilih o ljubljanskem urbanizmu.

Prvi možen način uporabe diskurzivne strategije je sestavljanje kategorij. Primer iz enega poljudnih besedil ponazarja, kako deluje: »... To bi lahko bil slovenski Tate Modern. "V stavku, ki govori o prenovi kompleksa Rog v središču Ljubljane, so različne pripovedne dimenzije združene v celoto. Pridevnik "slovenski« se nanaša na raven socialnega, medtem ko se samostalnik »Tate Modern" nanaša na raven prostorskega. Ključni problem $\mathrm{v}$ tej besedni zvezi je samoumevno združevanje dveh simbolno popolnoma različnih in neprenosljivih kategorij. Galerija Tate Modern v tem smislu nadomesti oz. je imaginarno postavljena na območje Roga in predstavlja ideal, h kateremu bi morali težiti pri prenovi kompleksa. Kar avtor stavka namerno zamolči, je specifičen in unikaten družbeno-prostorski kontekst ${ }^{[9]}$ galerije Tate Modern, zaradi česar gre za svetovno razpoznaven arhitekturni in nacionalni simbol. Ideje galerije Tate Modern s tega vidika ni mogoče uspešno »kopirati« oz. postaviti v drugačnem okolju in pričakovati podobne učinke na ravni mesta. $\mathrm{V}$ našem primeru avtor s sestavljanjem kategorij zakrije nezmožnost realizacije projekta oz. spodbuja identifikacijo z nekim idealotipskim projektom. Brez podajanja konkretnih in podrobnih načrtov prenove kompleksa ter z uporabo privlačne, a neuresničljive ideje pričakuje od bralca identifikacijo z njegovimi komentarji in podporo za njegove predloge o posegih v prostor. Wallwork in Dixon (2004: 33) zapišeta, da je: "... ta oblika klasifikacije zanimiva, ker spremeni v eksplicitno nekaj, kar je pogosto 
implicitno v okviru nacionalnih kategorij oz. ima tendenco, da zamolči družbeno v prostorskem«.

Metonimije so druga oblika diskurzivne strategije, ki jo pogosto opažamo v besedilih o ljubljanskem urbanizmu. Npr. v stavku: "Ljubljana je iz neznanih razlogov zavlačevala razglasitev ..." se zdi, kot da je pri odločitvi o zavlačevanju sodelovala vsa populacija v Ljubljani oz. vsi »Ljubljančani«, in ne pojasni, kateri posamezniki so dejansko udeleženi v dogodku. Kakorkoli banalne se zdijo take metonimije, opravljajo $\mathrm{v}$ besedilu nadvse pomembno funkcijo in vplivajo na bralca. Metonimično nadomeščanje namreč povzroči »vzpostavitev simbolične ekvivalence« (Wallwork, Dixon, 2004: 33) oz. enakovrednosti med Ljubljano kot geografskim pojmom in Ljubljančani kot družbeno skupino. Podobno Arnesen (citirano v: Wallwork, Dixon, 2004: 33) navaja, da metonimije oblikujejo »relacije kontingence (asociacije misli), pri čemer je ena kategorija lahko spremenjena v drugo kategorijo brez izgube osnovne identitete«. Metonimije pozivajo k reifikaciji oz. opredmetenju družbene skupine, katere člani niso jasno razpoznavni. Ko podpirajo nenehno zamenjevanje oz. nadomeščanje posameznega s splošnim, partikularnega z javnim, delčka s celoto, konkretnega $\mathrm{z}$ abstraktnim, dopuščajo določenim kategorijam, da pridobijo »realnost «, ki je obenem »človeška in nekako več kot človeška« (prav tam).

Tretji način prikrivanja sporočil oz. pomenov, ki jih sprožajo posegi v prostor, so antropomorfizmi. Antropomorfizmi delujejo tako, da »prisojajo človeške lastnosti in motivacije prostorom, pojavom zunaj človeka« (prav tam). Npr: "Ljubljana je mesto, ki žre svoje ideje ... «ali pa: »Ljubljana je iz sebe hotela nekaj narediti $\mathrm{v}$ tridesetih letih ... "Ta proces ima vrsto pomembnih vplivov na bralce, od katerih bomo omenili predvsem dva. Po eni strani lahko pomagajo prikriti interese ekonomskih, političnih skupin, ki se skrivajo pod določenim prikazom dogodkov. Tako antropomorfizmi pomagajo pri legitimizaciji posegov v prostor interesnih skupin. Po drugi strani pa lahko ustvarjajo podobo Ljubljane kot neodvisne entitete, ki ima sposobnost avtonomije odločanja oz. zmožnost, da deluje in se odziva na dogodke v prostoru. ${ }^{[10]}$ Zaradi teh razlogov so antropomorfične formulacije lahko močan dejavnik pri procesih eksternalizacije, uteleševanja in "pozabljanja«, ki so temelji reifikacije. Berger (1966) interpretira reifikacijo kot stanje amnezije, v kateri posameznik pozabi na človeški izvor družbenega sveta. Družbeni fenomeni so razumljeni kot »nekaj, kar ni proizvedeno s strani človeka - kot dejanje narave, rezultat kozmičnih zakonov ali manifestacij božanske volje« (Berger in Luckmann, 1966: 89). Berger in Pullberg (1966: 68) opisujeta stanje "pozabljivosti« kot obrambni mehanizem, s katerim se posameznik zavaruje pred enim »osnovnih strahov človeške eksistence, tj. strahom pred kaosom«.

\subsection{Identifikacija ključnih diskurzov}

Po analizi diskurzivnih strategij smo se osredotočili na identifikacijo ključnih diskurzov, ki smo jih prepoznali $\mathrm{v}$ besedilih o ljubljanskem urbanizmu. Zaradi velikega števila besedil smo uporabili filtracijske mehanizme, s katerimi smo besedila razvrstili glede na posamezne diskurze. Pri tem smo izdelali vrsto »frazeoloških slovarjev« in "pravil prenosa idej« (Bengston in dr., 2005: 1). Frazeološki slovarji so vključevali ključne besede, samostalnike, pridevnike in fraze, povezane s specifičnim diskurzom, ki smo ga želeli analizirati, medtem ko so nam pravila prenosa idej omogočila, da določimo, kako se pari besed in fraz kombinirajo ter ustvarjajo nove pomene. S pomočjo statističnega programa Textstat 2.6 smo izolirali besedila, ki so vsebovala besede iz naših slovarjev in ustrezala vnaprej določenim pravilom prenosa idej. Z uporabo tega selekcijskega mehanizma smo postopno locirali in diferencirali besedila, ki so vsebovala specifične diskurze. Prepoznali smo 15 različnih diskurzov, ki so jih avtorji bodisi namerno bodisi nenamerno vključili $\mathrm{v}$ besedilo in bi lahko potencialno vplivali na pasivnega bralca. ${ }^{[11]} \mathrm{V}$ Preglednici 2 so diskurzi razvrščeni glede na frekvenco njihove pojavnosti v celotnem naboru besedil o ljubljanskem urbanizmu.

Preglednica 2: Diskurzivne tipologije.

\begin{tabular}{|l|l|l|}
\hline Skupina $\mathbf{1}$ & Skupina 2 & Skupina 3 \\
\hline Strokovni diskurz & Planerski diskurz & Globalistični diskurz \\
\hline Nacionalistični diskurz & Lokalistični diskurz & Kulturalistični diskurz \\
\hline Katastrofični diskurz & Higienistični diskurz & Aktivistični diskurz \\
\hline Sistemski diskurz & Organicistični diskurz & Moralistični diskurz \\
\hline Neoliberalni diskurz & PR (public-relation) diskurz & \\
\hline Participativni diskurz & & \\
\hline
\end{tabular}

Vir: Kos, D. in dr. (2006) 
Primeri, ki so bili izbrani iz skupin strokovnih in časopisnih besedil, ilustrirajo, kako diskurzi delujejo. Primeri vključujejo strokovni, nacionalistični in katastrofični diskurz. (Preglednica 3)

Ena izmed pogostejših retoričnih strategij $\mathrm{v}$ strokovnih diskurzih ${ }^{[12]}$ je uporaba abstraktnih konceptov, besed in argumentacije, ki ni podprta s preverjenimi podatki in informacijami. Avtor besedila nagovarja bralca k sprejetju "strokovnega" znanja na podlagi zaupanja $v$ njegovo stroko. Retorična strategija temelji na domnevi, da bo bralec sprejel koncepte $\mathrm{v}$ besedilu brez zadržkov, avtorja pa identificiral kot »nekoga, ki ve resnico«. Princip, kjer se avtor samopercipira kot »deus ex machina«, je prikazan $\mathrm{v}$ prvih treh primerih strokovnega diskurza. V prvem primeru ni mogoče določiti, kdo natančno je del stroke, ki zahteva preverjanje specifičnih prostorskih načrtov. V drugem in tretjem primeru ni jasno razvidno, kdo predstavlja skupino strokovnjakov oz. kako je bila izbrana skupina strokovnjakov, ki je podala mnenje o izbrani lokaciji in tako $\mathrm{v}$ medijih bodisi podprla bodisi zavrnila predvidene prostorske načrte. ${ }^{[13]} \mathrm{V}$ četrtem primeru ni mogoče določiti razlike med znanstvenimi in strokovnimi primerjavami oz. gre za uporabo tavtologije, ki poudarja potrebo po uporabi stroke pri analizi prostorskega načrtovanja $\mathrm{v}$ Ljubljani. Peti primer je še ena značilna retorična strategija, ki jo pogosto opažamo v strokovnem diskurzu - avtor besedila poskuša narediti vtis na bralca $\mathrm{z}$ uporabo verige abstraktnih besed in konceptov.

Podobne retorične strategije, vendar $\mathrm{z}$ različnimi poudarki, opažamo tudi $\mathrm{v}$ nacionalističnem in katastrofičnem diskurzu. V nacionalističnem diskurzu so močno poudarjene simbolne vloge krajev, lokacij in stavb ter razlike med domačim oz. »domorodnim« in tujim. V prvem primeru povezovanje državnega praznika $\mathrm{z}$ novim gradbenim projektom implicira na širšo, nacionalno vlogo zastavljenega projekta oz. avtor »igra« na nacionalna čustva, da bi poudaril nujnost realizacije projekta. $V$ drugem, tretjem, četrtem in petem primeru se poskuša odnos investitorjev do domače stroke prikazati kot omalovažujoč, ker so bili na razpis povabljeni le tuji arhitekti. Pri tem avtorji izpostavljajo razlike med domačim (nacionalnim) in tujim (zunajnarodnim),

Preglednica 3: Primeri strokovnega, nacionalističnega in katastrofičnega diskurza.

\begin{tabular}{|c|c|}
\hline Diskurz & Primer \\
\hline Strokovni diskurz & $\begin{array}{l}\text { 1) „Stroka zahteva preveritev dosedanje strategije policentričnega razvoja in regionalizacije ..." } \\
\text { 2) »Pridobili so celo mnenje strokovnjakov, ki kažejo, da Kolizej nima tolikšne spomeniške vrednosti, kot mu jo } \\
\text { pripisujejo tisti, ki so ga zaščitili z odlokom.» } \\
\text { 3) »Strokovnjaki govorijo o 'njegovi izjemni urbanistični zasnovi', kar je pač res. A tudi ta stavba je videla hude čase, } \\
\text { že po dveh letih prvi večji požar, večkrat in še nedavno nevarne prezidave.» } \\
\text { 4) »Ljubljana kot prestolnica nove države in kot značilno srednjeevropsko mesto srednje velikosti je zanimiva za } \\
\text { znanstvene in strokovne primerjave." } \\
\text { 5) »V območju severnega dela EU smo tako priča intenzivnemu planiranju, projektiranju in gradnji osnov, ki } \\
\text { povezujejo relacije mobilnosti obsežnih teritorialnih bazenov in internacionalnih destinacij in ki usmerjajo } \\
\text { promet tudi globalnih ekonomij. Ta izhodišča so osnova za analizo opredelitev potreb pri usmerjanju strategije } \\
\text { prostorskega razvoja Slovenije ter razumevanja prostorskih razvojnih problemov pred oblikovanjem prioritet.» }\end{array}$ \\
\hline & $\begin{array}{l}\text { 1) »A dokler Kolizej ostaja spomenik lokalnega pomena, mora lastnik še vedno skrbeti zanj, čeprav ob 20-letnici } \\
\text { slovenske državnosti vidi na njegovem mestu novo kulturno srce Ljubljane.» } \\
\text { 2) Kolizej, nekdaj največja ljubljanska stavba, zdaj pa sramota, bodo na novo narisali uveljavljeni tuji arhitekti, } \\
\text { domači niti niso bili vabljeni na natečaj ... } \\
\text { 3) »Prve drobtinice bodo padle arhitektom, ki bodo zmagali na pravkar razpisanem natečaju, jako mednarodnem, } \\
\text { pravzaprav kar zunajnarodnem. Povabljeni so bili namreč samo tuji. Ali so domači povesili nosove - z izjemo } \\
\text { predsednika strokovne komisije, ki bo izbirala med projekti ..." } \\
\text { 4) "... številne kritike na račun naložbenika, ki je povabil k sodelovanju zgolj tuje arhitekte, nato pa ogorčenje } \\
\text { domačih arhitektov nad izbrano rešitvijo dveh Nizozemcev. Nista se namreč ozirala na merila (ali bolje: želje) } \\
\text { Ljubljane o kulturni dediččini, saj bi mirno podrla spomeniško zaščiteno stavbo Kolizeja ..." } \\
\text { 5) »... sprašuje, ali so za projekt potrebovali arhitekturne zvezde, saj bi kaj takega lahko naredili tudi domači.» }\end{array}$ \\
\hline $\begin{array}{l}\text { Katastrofični } \\
\text { (emocionalni) } \\
\text { diskurz }\end{array}$ & $\begin{array}{l}\text { 1) „Ali naj zahtevamo demonstracije na cestah: imate načrte, razrešite prometno katastrofo okoli Kliničnega centra, } \\
\text { kakor veste in znate, ampak začnite že? Začnite, začnite!" } \\
\text { 2) „Če samo pomislim, koliko nalog in zazidalnih preizkusov smo naredili, koliko regulacij, koliko študij mestnih } \\
\text { vpadnic, koliko je bilo natečajev, koliko prvih nagrad, koliko energije je šlo v nič! Kakšna škoda se dela stroki, ki } \\
\text { se ne more izkazati v tem mestu ... Tudi to je ena od pomembnih razsežnosti krize, v katero je padlo mesto: kriza } \\
\text { ustavljanja ustvarjalnega duha." } \\
\text { 3) „Če ljudje vidijo, da okolje propada, se sprijaznijo s tem in jemljejo kot nekaj samoumevnega. To je kot neka } \\
\text { oblika skupinske duševne bolezni, ki lega na ljudi, da se bojijo vsake novosti ..." }\end{array}$ \\
\hline
\end{tabular}

Vir: Kos, D. in dr. (2006) 
saj naj bi bili zadnji manj občutljivi za zahteve domačega okolja. V okviru katastrofičnega diskurza poskuša avtor besedila vplivati na občinstvo z uporabo posebno dramatičnega govora in besed, ki naj bi vzbudile emocije oz. čustvene odzive bralca. V prvem primeru katastrofičnega diskurza so tako omenjene demonstracije in večkratno pozivanje $\mathrm{k}$ premiku iz nastale prometne situacije. V drugem primeru se s ponavljanjem besed poskuša povečevati oz. stopnjevati napetost $\mathrm{v}$ besedilu, medtem ko se $v$ tretjem primeru uporablja pretiravanja, tj. propadanje okolja se $\mathrm{v}$ besedilu povezuje $\mathrm{z}$ obliko skupinske duševne bolezni.

Pomembno je pojasniti, da večina besedil vsebuje različne tipe diskurza. Kombinacija različnih diskurzov, ki skrivajo ali zakrivajo določene značilnosti posegov v prostor, nadgrajuje retorično strategijo, $\mathrm{s}$ katero se nagovarja bralce. Na primer sistemski diskurz se pogosto kombinira s planerskim in participativnim. Za sistemski diskurz je značilno, da avtor poudarja potrebo po sledenju formalnim postopkom in načrtom, se zavzema za intervencije države, vključevanje različnih vrst institucij, mestnih uprav itd. Takšne diskurzivne značilnosti se navadno skladajo s planerskim diskurzom, ki poudarja pomembnost dolgoročnega, srednjeročnega, kratkoročnega planiranja oz. načrtovanja, pripravo ustreznih načrtovalskih predlogov in participativnim diskurzom, kjer je poudarek na vlogi različnih akterjev oz. udeleženih pri prostorskem načrtovanju.

\section{Primerjava diskurzov $\mathrm{v}$ poljudnih in strokovnih besedilih}

Čeprav so se avtorji poljudnih besedil nagibali k pogostejši rabi »senzacionalističnega« Žargona oz. besedišča, ki je preprostejše in običajnejše v primerjavi s »strokovnim《 žargonom, je treba poudariti, da se strokovna besedila na ravni razprave niso dosti razlikovala od poljudnih. Namesto da bi avtorji strokovnih besedil poskušali natančno pojasniti načrtovalske postopke in posege $\mathrm{v}$ prostor ter se tako diferencirati oz. razločiti glede na avtorje poljudnih besedil, se zdi, da poskušajo »strokovnjaki« vse bolj približati svoja besedila poljudemu, senzacionalističnemu pisanju. Avtorji strokovnih besedil pišejo čedalje krajša besedila in poskušajo pritegniti bralce s poenostavljanjem besedišča.

$\mathrm{Na}$ primeru katastrofičnega diskurza bomo prikazali, kako majhne so razlike med skupinama poljudnih in strokovnih besedil. Katastrofični diskurz je opazen v obeh skupinah tekstov. Čeprav obstajajo določene razlike $\mathrm{v}$ njegovi uporabi, niso bile tako velike, kot smo predvidevali. Pri avtorjih strokovnih besedil smo pričakovali večje izogibanje katastrofičnemu diskurzu in dramatični naraciji. V nasprotju z našimi pričakovanji smo opazili podobnosti med obema skupinama besedil že na ravni statistične analize besedišča in fraz, ki so del katastrofičnega frazeološkega slovarja (Preglednica 4).

Preglednica 4: Primerjalna frekvenčna analiza besed iz frazeološkega slovarja katastrofičnega diskurza.

\begin{tabular}{|l|c|c|}
\hline $\begin{array}{c}\text { Koreni besed iz slovarja } \\
\text { katastrofičnega diskurza }\end{array}$ & $\begin{array}{c}\text { KP } \\
\text { Poljud. besed. }\end{array}$ & $\begin{array}{c}\text { KP } \\
\text { Strokov. besed. }\end{array}$ \\
\hline Kriz $^{*}$ & 0,006 & $\mathbf{0 , 0 1 1}$ \\
\hline Katastrof* $^{*}$ & $\mathbf{0 , 0 1 3}$ & 0,004 \\
\hline Propad* & $\mathbf{0 , 0 5 3}$ & 0,005 \\
\hline Degrad* & 0,01 & $\mathbf{0 , 0 1 5}$ \\
\hline Razvred* $^{*}$ & 0,001 & $\mathbf{0 , 0 0}$ \\
\hline Razjed $^{*}$ & 0,001 & 0 \\
\hline Ogroža* & 0,01 & 0,003 \\
\hline Unič* & $\mathbf{0 , 0 2 1}$ & $\mathbf{0 , 0 1 9}$ \\
\hline Usodn* & $\mathbf{0 , 0 0 8}$ & 0,002 \\
\hline Nesreč* $^{*}$ & $\mathbf{0 , 0 1 4}$ & 0,001 \\
\hline Sramot* & $\mathbf{0 , 0 0 5}$ & 0 \\
\hline Neprav* & $\mathbf{0 , 0 0 2}$ & 0,001 \\
\hline Barbar $^{*}$ & $\mathbf{0 , 0 0 2}$ & 0,001 \\
\hline Zanič* & $\mathbf{0 , 0 0 1}$ & 0 \\
\hline Kaos* $^{*}$ & $\mathbf{0 , 0 0 3}$ & 0,002 \\
\hline
\end{tabular}

Vir: Kos, D. in dr. (2006)

Repertoar in frekvenca besed, kot so:

kriz(a), propad, nesreč(a), katastrof(a), unič(enje), usodn(ost),

sta $\mathrm{v}$ poljudnih besedilih ponavadi večja kot $\mathrm{v}$ strokovnih, vendar tudi avtorji strokovnih besedil pogosto uporabljajo besede kot: degrad(acija), unič(enje) itd. Pri posameznih besedah (npr. kriz(a), degrad(acija) in razvred(notenje)) iz slovarja katastrofičnega diskurza je frekvenca njihove uporabe celo večja v strokovnih kot poljudnih besedilih.

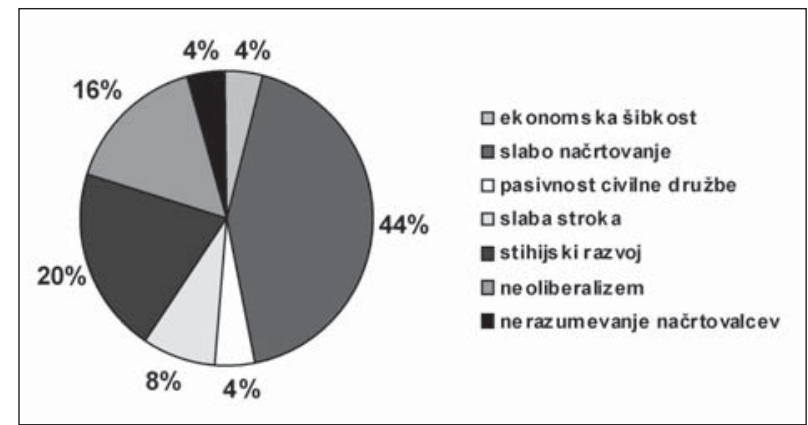

Slika 2: Tematike $v$ poljudnih besedilih $\mathrm{s}$ katastrofičnim diskurzom. (Vir: Kos, D. in dr., 2006) 
Uporaba podobnega slovarja nedvomno prispeva $\mathrm{k}$ zmanjševanju razlik med senzacionalističnim (formalno-deklarativnim) in strokovnim (vsebinsko-argumentatitivnim) jezikom $\mathrm{v}$ besedilih.

Primerjalna analiza ključnih tematik oz. razlogov, zaradi katerih je bil uporabljen katastrofični diskurz, kaže skoraj identične rezultate. Identificirali smo sedem ključnih tematik, ki so bile običajno povezane s katastrofičnim diskurzom. Sliki 2 in 3 v odstotkih kažeta prisotnost posameznih tematik v besedilih, ki vsebujejo katastrofični diskurz. ${ }^{[14]}$

Rezultati so pokazali, da imajo poljudna v primerjavi s strokovnimi besedili širši razpon, ki so povezani s katastrofičnim diskurzom. Najpogosteje uporabljena

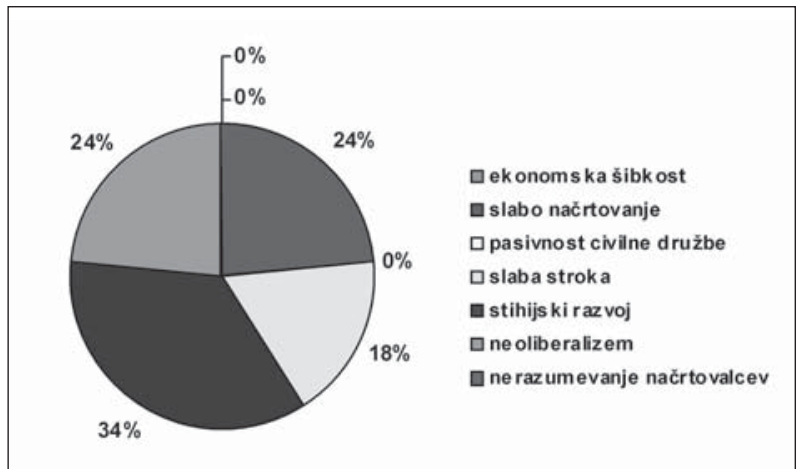

Slika 3: Tematike v strokovnih besedilih s katastrofičnim diskurzom. (Vir: Kos, D. in dr., 2006) tematika, kjer se uporablja katastrofični diskurz v poljudnih besedilih, opisuje slabo prostorsko načrtovanje ( 44 odstotkov), ki mu sledijo stihijski razvoj in brezvladje (20 odstotkov), učinki neoliberalizma (16 odstotkov), nezadovoljstvo s stroko (osem odstotkov) ter ekonomska šibkost sistema, pasivnost civilne družbe in nerazumevanje načrtovalcev $\mathrm{v}$ javnosti (vsi po štiri odstotke). Avtorji strokovnih besedil Z uporabo katastrofičnega diskurza največkrat izražajo nezadovoljstvo s stihijskim razvojem (34 odstotkov), ki mu sledita slabo prostorsko načrtovanje in neoliberalizem (oba po 24 odstotkov).

Kljub razlikam v deležih, ki se kažejo v uporabi katastrofičnega diskurza za posamezne tematike, se prevladujoče tematike $\mathrm{v}$ poljudnih in strokovnih besedilih približno pokrivajo (Slika 4). Prve štiri tematike med poljudnimi besedili se pokrivajo s prvimi štirimi tematikami, ki jih opažamo v strokovnih tekstih. Vrstni red pomembnosti posameznih tematik $\mathrm{v}$ poljudnih in strokovnih besedilih je skoraj enak, zamenjan je le vrstni red prve in druge tematike. Razlogi oz. kontekst, v katerem katastrofični diskurz uporabljajo pisci poljudnih in strokovnih besedil, se torej skorajda skladajo. Prav na osnovi teh skladnosti lahko sklepamo, da so razlike med strokovnimi in poljudnimi besedili dokaj majhne.

Sorazmerno majhne razlike med dvema skupinama besedil so lahko problematične zaradi različnih razlogov, ki vplivajo na bralčevo razumevanje posegov

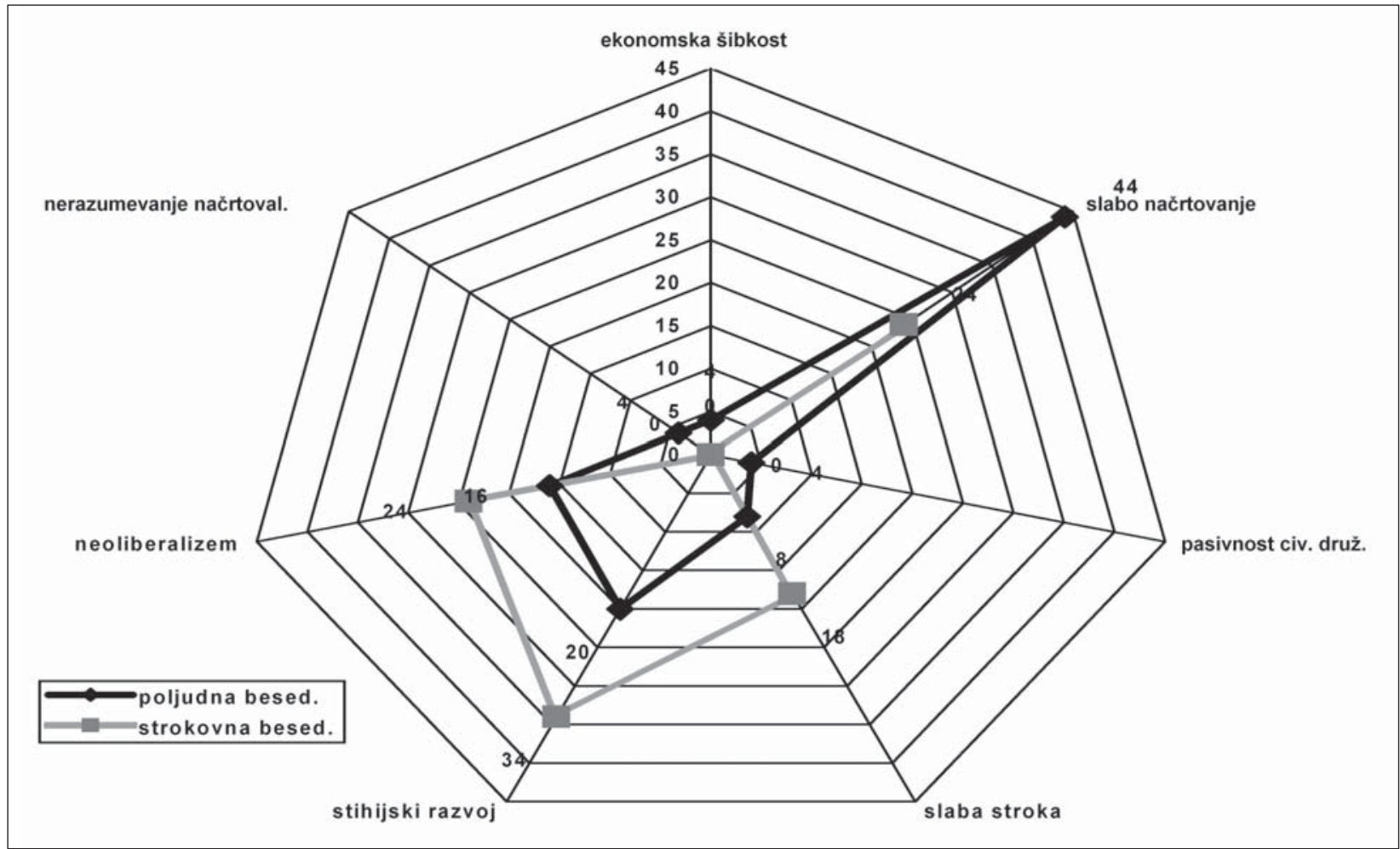

Slika 4: Primerjava tematik v poljudnih in strokovnih besedilih s katastrofičnim diskurzom. (Vir: Kos, D. in dr., 2006) 
v prostor. Crusikshank (2003: 14) ugotavlja, da: »če znova in znova poslušamo podobne opise situacije, prek medijev ali politikov, brez dostopa do alternativnih opisov, potem se ti opisi generalizirajo in postanejo del vsakdanje kulture in skupne zaloge znanja«. Pri tem domnevamo, da so avtorji strokovnih besedil pripravljeni za pridobivanje večjega občinstva zniževati standarde pisanja in uporabljati podobno besedišče in tematike, ki smo jih opazili v poljudnih besedilih.

Zanimivo je, da poskušajo avtorji strokovnih besedil kljub zniževanju standardov pisanja zadržati svoj privilegirani položaj »strokovne reference« oz. svetovalca civilni družbi o posegih v prostor. Zadržati poskušajo svojo strokovno skupino neodvisno oz. rezervirano $\mathrm{v}$ odnosu do zunanjih vplivov, zato se ne le pogosto odločajo za uporabo nacionalističnega diskurza, temveč se poskušajo tudi zavarovati pred interdisciplinarnostjo. Nepovezanost med strokami (arhitekturo, krajinsko arhitekturo, urbanizmom, sociologijo itd.) oz. zaviranje razvoja interdisciplinarnosti se izvaja $z$ uporabo sistemsko-abstraktnega diskurza, ki »neposvečene« izloča iz razprave. Avtorji strokovnih besedil pogosto uporabljajo besede in izraze, ki so terminološko povezani z njihovo stroko in analizirajo aktualne probleme samo deskriptivno, brez namenjanja pozornosti širšim povezavam in posledicam posegov $\mathrm{v}$ prostor. S pogosto uporabo sistemsko-abstraktnega diskurza večinoma ne ponujajo konkretnih rešitev analizirane problematike in tako zavirajo razvoj pestrejše javne razprave o aktualnih problemih.

Sistemsko-abstraktni diskurz $\mathrm{v}$ strokovnih besedilih se pogosto združuje s političnim diskurzom, ki poudarja vlogo trajnostnega razvoja in »evropskega« prostorskega načrtovanja. Ker ne obstajajo jasne definicije trajnostnega razvoja in evropskega prostorskega načrtovanja, avtorji strokovnih besedil brez nujno potrebne kritične distance pogosto povzemajo ideje in koncepte iz zelo splošnih usmeritvenih dokumentov, kot je evropska Bela knjiga (2000) o varovanju okolja. Povzete ideje in koncepti zato pogosto niso zadostno razdelani oz. integrirani in prilagojeni lokalnim okoliščinam in trendom, ki narekujejo prostorski razvoj v Ljubljani. Avtorji strokovnih besedil pogosto napačno interpretirajo generalizirane evropocentrične ideje in koncepte kot orodje, ki bo avtomatično rešilo lokalno specifične prostorske probleme.

Kvalitativna analiza besedil pokaže, da so v veliko primerih poljudna besedila precej bolj kritična, bolj aplikativno usmerjena in imajo kompleksnejšo argumentativno strukturo kot strokovna besedila. $\mathrm{Na}$ osnovi teh primerov lahko domnevamo, da proces zmanjševanja razlik ne poteka enosmerno, temveč velja za obe skupini besedil. Avtorji strokovnih besedil poskušajo znižati standarde pisanja in doseči širšo ciljno publiko, medtem ko poskušajo avtorji poljudnih besedil izboljšati raven svoje prepričljivosti s privzemanjem strokovnih argumentativnih strategij in besedišča. Ta sinergični proces nenehnega prepletanja različnih diskurzov se označuje kot »intertekstualnost«[15] (Fairclough, 1992: 84-85).

Pomembno je omeniti, da se kompleksnih procesov artikulacije diskurzov ne more pojasnjevati zgolj z analizo besedil. Poleg zniževanja standardov pisanja avtorjev strokovnih besedil in »izpopolnjevanja« avtorjev poljudnih besedil obstaja še vrsta dejavnikov, ki prispevajo k zmanjševanju razlik med skupinami besedil. Ti dejavniki lahko vključujejo zmanjševanje javnega zanimanja za kompleksne ekspertize, zmanjševanje kritične mase zainteresiranih intelektualcev, strokovnjakov in še posebno specifičen kontekst slovenskih tiskanih medijev. Način distribucije novic in informacij je bil $\mathrm{v}$ tranzicijskem obdobju $\mathrm{z}$ uvedbo tržne ekonomije na področju medijev radikalno spremenjen. Richardson (2007: 78) opozarja na dvosmerni proces intenzivne "fragmentacije občinstva«, pri čemer je občinstvo dojeto bodisi kot "potrošnik« bodisi kot »potrošno blago«. Glede na prvi vidik postajajo besedila čedalje zanimivejša in privlačnejša za širok trg potrošnikov, medtem ko so z drugega vidika dojeta kot oblika dostopa do občinstva Oz. oglaševalski prostor. Če je prvi način fragmentacije občinstva, ki poteka po načelu od spodaj navzgor, ${ }^{[16]}$ razumljiv $\mathrm{z}$ vidika povečevanja dobička, ima drugi način, tj. od zgoraj navzdol, lahko precej bolj destruktivne učinke z oblikovanjem javnega mnenja in zagovarjanjem javnih interesov. Pristop od zgoraj navzdol je značilen za medijsko produkcijo, ki poskuša segmentirati oz. kategorizirati občinstva in s prepričevalnimi strategijami vplivati na odločitve skupin in posameznikov, da bi dosegati cilje, kakršen je npr. legitimizacija določenih posegov $\mathrm{v}$ prostor.

\section{Sklep}

Analiza besedil je razkrila pomembne razlike in podobnosti pri izbiri retoričnih strategij med različnima žanroma. Zmanjševanje razlik med dvema skupinama besedil je posebno problematično zaradi naraščanja »interpretativnega vakuuma « avtorjev strokovnih besedil in pomanjkljivega opisovanja prostorskih procesov ter uporabe čedalje bolj preprostega, senzacionalističnega besedišča. To prispeva $\mathrm{k}$ zmanjševanju institucionalne in individualne refleksije ter omogoča ekonomskim interesnim 
skupinam lažje doseganje potrebne legitimnosti ${ }^{[17]}$ za posege v prostor. Avtorji strokovnih besedil bi v tem kontekstu morali zasedati pomembnejšo vlogo $\mathrm{v}$ »javni sferi« (Habermas, 1962/1991: 176) in poosebljati oz. spodbujati neodvisna mnenja, ki izključujejo vplive političnih in ekonomskih skupin.

Avtorje strokovnih besedil se pogosto prikazuje kot predstavnike javne sfere, ki so nekakšno varovalo oz. kritična protiutež za interesne skupine, ki poskušajo uveljavljati zasebne in potlačiti javne interese. V našem raziskovalnem projektu analize besedil se je pokazalo, da so strokovna besedila o ljubljanskem urbanizmu pogosto »razredčena« oz. omiljena $\mathrm{z}$ izpostavljanjem izrazito kritičnih mnenj o posegih $\mathrm{v}$ prostor. Vloga »strokovnjakov« v besedilih o ljubljanskem urbanizmu ni popolnoma jasna in ne obstaja t. i. »idealna govorna situacija« (Habermas, 1984: 177), ki bi vodila h konsolidaciji javnega kritičnega foruma, na katerem bi se odkrito soočili zagovorniki zasebnih in javnih interesov $\mathrm{v}$ prostorskem načrtovanju. Obdobje tranzicije je bilo nedvomno pomemben dejavnik v razkroju starih prostorskih hierarhij in avtoritet, ki so bile pomembna sila pri oblikovanju javnega mnenja. Razpad starih hierarhij ni pomenil le odprtja prostora za nove državno-institucionalne akterje pri oblikovanju javnega mnenja, temveč je pustil tudi ogromno praznega prostora, ki so ga nenehno polnile oglaševalske skupine. Nekonsolidirana struktura javnega kritičnega foruma o prostorskem načrtovanju ponuja veliko možnosti za vplive različnih ekonomskih interesnih skupin na diskurzivne prakse avtorjev poljudnih in strokovnih besedil.

Razmere, v katerih so mnenjski voditelji oz. strokovne avtoritete šibki in jih čedalje bolj nadomešča strokovni interpretativni vakuum, lahko opišemo tudi kot tendence »motivacijske krize« (Habermas, 1976: 75-76). Po Habermasu (prav tam) motivacijske krize nastanejo, ko se družbeno-kulturni sistem spremeni in njegovi učinki postanejo nefunkcionalni za nosilce političnih odločitev in sistem družbenega dela. Učinki motivacijske krize vplivajo na politično ravnanje in javno udeležbo oz. aktivizem posameznikov. Zaradi hitrih in radikalnih sprememb $\mathrm{v}$ politiki in gospodarstvu se posamezniki pogosto srečujejo z nemočjo in izključenostjo pri odločanju/ sodelovanju v družbenopolitičnem procesu. Ker je $\mathrm{v}$ veliko situacijah njihova politična aktivnost oz. vključevanje $\mathrm{v}$ javnost soočeno $\mathrm{z}$ močnimi zagovorniki zasebnih interesov, to vodi v pasivizacijo in "podrejeno mentaliteto ljudi v odnosu do političnih elit« (prav tam). Ljudje težijo k depolitizaciji in umiku iz javne diskusije.

Ronald Inglehart (1997), ki je analiziral kulturne vrednote nacionalnih družbenoekonomskih sistemov v evropskih državah (World Values Survey, 1995, 1996, 1997), je ugotovil, da ekonomski razvoj igra izredno pomembno vlogo pri spreminjanju obstoječih/sprejetih družbenih vrednot (internet 1 in 2). Pri razpravljanju o različnih ritmih pri premikih vrednot v zahodnih evropskih državah Inglehart (1997) poudarja ujemanje/skladanje/ ekonomske rasti in družbenega razvoja. ${ }^{[18]}$ Izboljšanje ekonomskih razmer, družbene varnosti in izobraževalnih, zaposlitvenih možnosti lahko sproži premik k postmaterialističnim vrednotam (označujejo jih večji poudarek na samoekspresivnosti, kakovost življenja in odnos do lastnine), prek katerih se čedalje bolj poudarja pomen varovanja prostora in skrbnega prostorskega načrtovanja.

Inglehart (1990) ugotavlja, da ima precej srednjeevropskih držav (Slovenija, Česka, Slovaška) zaradi vplivov tranzicijskega obdobja še vedno močne materialistične orientacije. Te nedvomno vplivajo na rigidnost družbenopolitičnih diskurzov o prostorskem načrtovanju. Nekateri avtorji (Deth, Scarbrough, 1998; Turnšek in dr., 2000) ob tem dodajajo, da so bile v obdobju po letu 1995 opažene določene spremembe $\mathrm{k}$ postmaterialističnim vrednotnim orientacijam. Če to drži, bi morali procesi sprejemanja konceptov in strategij, ki spodbujajo javno udeležbo $\mathrm{v}$ diskusijah o prostorskem načrtovanju, na dolgi rok preglasiti oz. premagati tendence, ki vodijo $\mathrm{v}$ motivacijsko krizo. Ko bodo kumulativni učinki vrste dolgoročnih investicij $\mathrm{v}$ izpopolnjevanje izobraževalne strukture, povečevanje pomena ekspertnih skupin in nevladnih organizacij začeli pridobivati pomen, se bo prostor javne sfere razširil in dopuščal večje možnosti za participacijo zdaj pasivnih akterjev v prostorskem načrtovanju. Šele ko bodo ljudje resnično sprejeli, tj. ponotranjili redefinicije obstoječih družbenih vrednot $\mathrm{v}$ novih političnih in ekonomskih razmerah, se bo na ravni vsakdanjega življenja zgodila dejanska implementacija postopkov, ki dopuščajo večjo in aktivnejšo javno participacijo pri prostorskem načrtovanju.

\section{Dr. Matjaž Uršič, univ. dipl. soc.}

Center za prostorsko sociologijo, Univerza v Ljubljani, Fakulteta

za družbene vede

E-pošta: matjaz.ursic2@guest.arnes.si

\footnotetext{
Opombe

[1] Projekt je financirala Mestna občina Ljubljana in je bil izveden v Centru za prostorsko sociologijo na Fakulteti za družbene vede, Univerze v Ljubljani. Skupino raziskovalcev so sestavljali: Drago Kos, Matjaž Uršič, Marjan Hočevar in Franc Trček.

[2] To ustreza približno 850 stranem teksta (1.800.000 znakov)

[3] Nekatera besedila so bila dostopna le $v$ tiskani verziji in jih je bilo treba konvertirati v digitalno obliko oz. zapis z uporabo programske opreme, kot sta Textbribge Pro 11.0 in Recognita Plus 3.2.
} 
[4] Publikacije: AB - Arhitektov Bilten, Urbani izziv ipd.

[5] Publikacije: Dnevnik, Delo, Večer, Mladina, Nedeljski dnevnik ipd.

[6] Večji ko je koeficient pogostosti termina (KP), večja je frekvenca uporabe določene besede $v$ tekstih o ljubljanskem urbanizmu. Koeficient pogostosti termina je bil izračunan po formuli KP $=(T F / S ̌ B) *$ 100 (Simbol TF predstavlja frekvenco določenega termina, medtem ko je ŠB skupno število besed $v$ določeni skupini besedil).

[7] $\vee$ Preglednici 1 so podani le posamezni primeri korenov besed. Npr koren dostop* lahko ustreza terminu dostopnost, dostop, dostopn ipd.

[8] Wallwork in Dixon (2004) opisujeta diskurzivne strategije kot tihe opomnike o obstoju »zunanje« realnosti sveta - realnosti, ki se jo, čeprav jo je ustvaril človek, dojema kot materialno dejstvo. Diskurzivne strategije lahko poudarjajo in spreminjajo vsebino s tem, da »določajo bodisi enovito bodisi parcialno stanje stvari $v$ diskurzivnem svetu« (Polanyi in Reitter, 1996: 14)

[9] Pri tem mislimo predvsem na popolnoma drugačne širše družbenoprostorske razmere (zgodovina, velikost mesta, države, različnost kultur itd.), v katere je umeščen projekt.

[10] $\vee$ nekaterih pogledih so antropomorfizmi podobni »organicizmu« (Rotar, 1985: 102-109), za katerega so značilni izrazi, ki mesto enačijo s človeškim telesom. Npr: »Mesto je kot telo; ceste so arterije in žile, ki v mesto vnašajo nujno potrebne snovi in produkte."

[11] Za raziskavo smo pasivne bralce identificirali kot bralce, ki premalo reflektirajo širši kontekst nastanka besedila (politične okoliščine, družbeni kontekst, uredniško politiko, finančno shemo publikacije, distribucijo itd.). Pasivni bralci so bolj nagnjeni k preprostemu sprejemanju oz. ponotranjenju idej in predstav, ki so v besedilih zapisane kot objektivne resnice.

[12] Strokovni diskurz smo identificirali s pomočjo posebnega frazeološkega slovarja, $v$ katerega so bile vključene besede kot: stroke, strokovnost, strokovnjak, specialist, ekspert, interdisciplinarnost, razvoj, varstvo okolja, varstvo dediščine itd.

[13] $\vee$ prvih treh primerih ne gre dejansko za strokovni diskurz, ampak diskurz, ki se intertekstualno sklicuje na diskurz urbanistične stroke oz. išče reference, utemeljitve $v$ abstraktnih strokovnih avtoritetah.

[14] Skupno število poljudnih in strokovnih besedil, ki vsebujejo katastrofični diskurz, je bilo 52. Zaradi različnega števila člankov v vsaki skupini besedil so deleži izračunani na osnovi skupnega koeficienta.

[15] Fairclough razume koncept intertekstualnosti kot »... značilnost tekstov, ki pomeni, da so teksti polni drobcev iz drugih tekstov, ki so implicitno razmejeni ali spojeni s prvotnim tekstom. Ta jih lahko bodisi asimilira, jim ugovarja, jih ironizira in tako dalje« (Chouliraki in Fairclough, 1999: 199)

[16] Fragmentacija občinstva je rezultat naraščanja možnosti izbire med vrsto medijev z najrazličnejšimi vsebinami.

[17] Gre predvsem za doseganje javne podpore in konsenza oz. sprejemljivosti posegov $v$ prostor od večine akterjev, ki se jim bo zato spremenila kakovost življenja.

[18] Kontekst družbenega razvoja je med drugim povezan z obsegom javnega interesa za prostorsko načrtovanje in varovanje okolje.

\section{Viri in literatura}

Bengston, N., Potts, D., Fan, S. R., David, P. in Goetz, G. E. (2005) An Analysis of the Public Discourse about Urban Sprawl in the United States: Monitoring Concern about a Major Threat to Forests. Forest Policy and Economics, 7, str. 745-756.

Berger, P. in Luckmann, T. (1966) The Social Construction of Reality. Garden City, N.Y., Anchor.

Berger, P. in Pullberg, S. (1966) Reification and the sociological critique of consciousness. New Left Review, 35, str. 56-77.
Chouliaraki, L. in Fairclough, N. (1999) Discourse in Late Modernity Rethinking Critical Discourse Analysis. Edinburgh, Edinburgh University Press.

Cruikshank, J. (2003) How are Ideas about Rurality Constructed - A Methodological Design. Paper at NOLD 2003, Tromsø, Norway, Regional Development in Place. Between the Cultures of Economic Development and the Economics of Cultural Production, Kristiansand.

Deth, W. J. in Scarbrough, E. (1998) The Impact of Values. Oxford, Oxford University Press.

Fairclough, N. (1992) Discourse and Social Change. Cambridge, Polity Press.

Fairclough, N. (1995) Critical Discourse Analysis. London, Longman.

Gregory, D. (1986) Spatial Structure, v: Johnston R. J. in dr. (ur.) The Dictionary of Human Geography. Oxford, Blackwell.

Habermas, J. (1976) Legitimation Crisis. London, Heinemann Educational Books.

Habermas, J. (1984) The theory of communicative action, volume 1, Reason and the rationalization of society. Boston, Beacon Press.

Habermas, J. (1962/1991) The Structural Transformation of the Public Sphere: An Inquiry into a category of Bourgeois Society. Cambridge, MA, MIT Press.

Inglehart, R. (1997) Modernization and postmodernization: cultural, economic, and political change in 43 societies. Princeton, N. J., Princeton University Press.

Internet 1: http://www.esds.ac.uk/International/access/wvs.asp (sneto 4. 2. 2006)

Internet 2: http://www.worldvaluessurvey. org (sneto 5. 2. 2006)

Jaworsky, A. in Coupland, N. (1999) Introduction: Perspectives on Discourse Analysis, v: Jaworsky A. in Coupland N. (ur.) The Discourse Reader, str. 1-45. London, Routledge.

Kos, D., Uršič, M., Hočevar, M. in Trček, F. (2006) Diskurzivna analiza o (ljubljanskem) urbanizmu - končno poročilo. Ljubljana, CPS, Fakulteta za družbene vede, Mestna občina Ljubljana.

Office for Official Publications of the European Communities (2000) The White Paper on Environmental Liability. Luxembourg.

Pahl, R. E. (1977) Managers, technical experts and the state, v: Harloe, M. (ur.) Captive cities: studies in the political economy of cities and regions, str. 49-60. London, New York, Wiley.

Potter, J. in Wetherell, M. (1987) Discourse and Social Psychology. London, Sage.

Reitter, D. (2003) Rhetorical Analysis with Rich-Feature Support Vector Models. Potsdam, University of Potsdam.

Richardson, E. J. (2007) Analysing Newspapers. Houndmills, Basingstoke, Hampshire, New York, Palgrave Macmillan.

Rotar, B. (1985) Risarji: učenjaki - Ideologije v urbanizmu in arhitekturi. Ljubljana, Delavska enotnost.

Salovaara-Moring, I. (2004) Media Geographies - Regional newspaper discourses in Finland in the 1990s. Helsinki, Department of Communication, University of Helsinki.

Shapiro, G. in Markoff, J. (1997) A Matter of Definition, v: Roberts C. W. (ur.) Text Analysis for Social Sciences: Methods for Drawing Statistical Inferences From Texts and Transcripts, str. 9-34. Mahwah, New Jersey, Lawrence Erlbaum Associates Publishers.

Turnšek, N., Uhan, S., in Gregorčič, M. (2000) Nekaj značilnosti v kulturi prebivalcev Slovenije v obdobju od leta 1991 do leta 1997. IB revija, 34(2), str. 61-71.

Wallwork, J. in Dixon, A. J. (2004) Foxes, green fields and Britishness: On the rhetorical construction of place and national identity. British Journal of Social Psychology, 43, str. 21-39.

Wodak, R. in Meyer, M. (2001) Methods of critical discourse analysis. London, Sage. 